\title{
Adenosine Deaminase Inhibitor EHNA Exhibits a Potent Anticancer Effect Against Malignant Pleural Mesothelioma
}

\author{
Yasuhiro Nakajima ${ }^{a}$ Takeshi Kanno $^{b}$ Toshio Nagaya ${ }^{c}$ Kozo Kuribayashia \\ Takashi Nakano ${ }^{a}$ Akinobu Gotoh ${ }^{c}$ Tomoyuki Nishizaki ${ }^{b}$
}

aDivision of Respiratory Medicine, Department of Internal Medicine, ${ }^{b}$ Division of Bioinformation, Department of Physiology and Laboratory of Cell and Gene Therapy Institute for Advanced Medical Sciences, Hyogo College of Medicine, Nishinomiya, Japan

\section{Key Words}

Adenosine deaminase inhibitor $•$ EHNA • Malignant pleural mesothelioma • Apoptosis

\begin{abstract}
Background/Aims: Malignant pleural mesothelioma (MPM) is an aggressive malignant tumor and an effective therapy has been little provided as yet. The present study investigated the possibility for the adenosine deaminase (ADA) inhibitor EHNA as a target of MPM treatment. Methods: MTT assay, TUNEL staining, monitoring of intracellular adenosine concentrations, and Western blotting were carried out in cultured human MPM cell lines without and with knocking-down ADA. The in vivo effect of EHNA was assessed in mice inoculated with NCI-H2052 MPM cells. Results: EHNA induced apoptosis of human MPM cell lines in a concentration (0.01-1 mM)- and treatment time (24-48 h)-dependent manner, but such effect was not obtained with another ADA inhibitor pentostatin. EHNA increased intracellular adenosine concentrations in a treatment time (3-9 h)-dependent manner. EHNA-induced apoptosis of MPM cells was mimicked by knocking-down ADA, and the effect was neutralized by the adenosine kinase inhibitor ABT-702. EHNA clearly suppressed tumor growth in mice inoculated with NCI-H2052 MPM cells. Conclusion: The results of the present study show that EHNA induces apoptosis of MPM cells by increasing intracellular adenosine concentrations, to convert to AMP, and effectively prevents MPM cell proliferation. This suggests that EHNA may be useful for treatment of the tragic neoplasm MPM.
\end{abstract}

Prof. Tomoyuki Nishizaki

KARGER 125
Division of Bioinformation, Department of Physiology, Hyogo College of Medicine, 1-1 Mukogawa-cho, Nishinomiya 663-8501 (Japan)

Tel. +81-798-45-6397, Fax +81-798-45-6649, E-Mail tomoyuki@hyo-med.ac.jp 


\section{Cellular Physiology and Biochemistry}

Cell Physiol Biochem 2015;35:51-60

DOI: $10.1159 / 000369674$

\section{Introduction}

Malignant pleural mesothelioma (MPM), a highly aggressive neoplasm, has been increasing in incidence globally [1]. Previous exposure to asbestos fibers essentially contributes to the pathogenesis of MPM, which is characterized by insidious growth and chemotherapy resistance with poor prognosis. In spite of extensive and intensive challenges, MPM therapy has been still limited to marginally effective chemotherapy and morbid surgery.

Accumulating evidence has pointed to adenosine-induced apoptosis in a variety of cancer cells, largely as mediated through intrinsic and/or extrinsic pathways. For the intrinsic pathway, extracellular adenosine is taken into cells by adenosine transporters and converted to AMP by adenosine kinase to activate AMP-activated protein kinase (AMPK), responsible for apoptosis in GT3-TKB human lung cancer cells and HuH-7 human hepatoma cells [2, 3]. Intracellularly transported adenosine also induces apoptosis in a caspase-dependent or -independent manner in HuH-7, HepG2 human hepatocellular carcinoma, MCF-7 human breast cancer, or human MPM cells [3-8]. For the extrinsic pathway, adenosine receptors, which include $A_{1}, A_{2 a^{\prime}} A_{2 b}$, and $A_{3}$ receptors, mediate apoptosis. Adenosine induces apoptosis in CW2 human colonic cancer cells and RCR-1 rat astrocytoma cells via $\mathrm{A}_{1}$ adenosine receptor $[9,10]$. Adenosine induces apoptosis in Caco-2 human colonic cancer and HepG2 cells via $\mathrm{A}_{2 \mathrm{a}}$ adenosine receptor $[11,12] . \mathrm{A}_{3}$ adenosine receptor mediates apoptosis in human lung cancer cells, hepatocellular carcinoma cells, thyroid cancer cells, breast cancer cells, renal cancer cells, bladder cancer cells, and MPM cells by the diverse independent mechanisms [13-20].

Adenosine is broken down into inosine by adenosine deaminase (ADA). ADA inhibition should raise adenosine concentrations by preventing adenosine breakdown. Then, we postulated that the ADA inhibitor erythro-9-(2-hydroxy-3-nonyl)adenine (EHNA) could exert its antitumor action against a variety of cancers. We show here that EHNA has the potential to induce apoptosis of MPM cells and suppress tumor growth in mice inoculated with NCI-H2052 cells.

\section{Materials and Methods}

\section{Cell culture}

Human MPM cell lines such as NCI-H28, NCI-H2052, NCI-H2452, and MSTO-211H cells were purchased from American Type Culture Collection (Manassas, VA, USA). Cells were grown in RPMI-1640 medium supplemented with 10\% heat-inactivated fetal bovine serum (FBS), 0.003\% L-glutamine, penicillin (final concentration, $100 \mathrm{U} / \mathrm{ml}$ ), and streptomycin (final concentration, $0.1 \mathrm{mg} / \mathrm{ml}$ ). Human lung cancer cell lines A549, SBC-3, and Lu-65 cells were purchased from Health Science Research Resources Bank (Osaka, Japan). A549 and SBC-3 cells were grown in minimum essential medium (MEM) containing $0.1 \mathrm{mM}$ non-essential amino acids and Lu-65 cells in RPMI-1640 medium supplemented with 10\% (v/v) heat-inactivated FBS, penicillin (final concentration, $100 \mathrm{U} / \mathrm{ml}$ ) and streptomycin (final concentration, $0.1 \mathrm{mg} / \mathrm{ml}$ ). Human hepatic cancer cell lines HepG2 and HuH-7 cells, obtained from RIKEN cell bank (Ibaraki, Japan), were cultured in Dulbecco's Modified Eagles Medium (DMEM) supplemented with 10\% (v/v) heat-inactivated FBS, penicillin (final concentration, $100 \mathrm{U} / \mathrm{ml}$ ) and streptomycin (final concentration, $0.1 \mathrm{mg} / \mathrm{ml}$ ). All the cells were incubated in a humidified atmosphere of $5 \% \mathrm{CO}_{2}$ and $95 \%$ air at $37^{\circ} \mathrm{C}$.

Assay of cell viability

Cell viability was evaluated by the method using 3-(4,5-dimethyl-2-thiazolyl)-2,5-diphenyl-2Htetrazolium bromide (MTT).

Terminal deoxynucleotidyl transferase-mediated dUTP nick end labeling (TUNEL) staining

TUNEL staining was performed to detect in situ DNA fragmentation as a marker of apoptosis using an In Situ Apoptosis Detection Kit (Takara Bio, Otsu, Japan). Briefly, fixed and permeabilized cells were 


\section{Cellular Physiology and Biochemistry}

Cell Physiol Biochem 2015;35:51-60

DOI: $10.1159 / 000369674$

Published on Ine: January 02, 2015

(c) 2015 S. Karger AG, Basel

www.karger.com/cpb

reacted with terminal deoxynucleotidyl transferase and fluorescein isothiocyanate (FITC)-deoxyuridine triphosphate for $90 \mathrm{~min}$ at $37^{\circ} \mathrm{C}$. FITC signals were visualized with a confocal scanning laser microscope (LSM 510, Carl Zeiss Co., Ltd., Oberkochen, Germany).

\section{Construction and transfection of siRNA}

The siRNA to silence human ADA-targeted gene (ADA siRNA) and the negative control siRNA (NC siRNA) were purchased from Santa Cruz Biotechnology (Santa Cruz, CA, USA). The ADA siRNA or the NC siRNA was reverse-transfected into cells using a Lipofectamine reagent (Invitrogen, Carlsbad, CA, USA). Cells were used for experiments $48 \mathrm{~h}$ after transfection.

\section{Western blotting}

Cells transfected with the $A D A$ siRNA or the $N C$ siRNA were lysed in lysis buffer [150 mM NaCl, $20 \mathrm{mM}$ EDTA, $0.5 \%(\mathrm{v} / \mathrm{v})$ Nonidet P-40 and $50 \mathrm{mM}$ Tris, $\mathrm{pH}$ 7.4] containing $1 \%(\mathrm{v} / \mathrm{v})$ protease inhibitor cocktail and $1 \%(\mathrm{v} / \mathrm{v})$ phosphatase inhibitor cocktail (Nacalai Tesque, Kyoto, Japan), and then centrifuged at $800 \mathrm{~g}$ for 5 min at $4{ }^{\circ} \mathrm{C}$. The supernatant was used as total cell lysate.

For Western blotting, proteins were separated by sodium dodecyl sulfate-polyacrylamide gel electrophoresis and then transferred to polyvinylidene difluoride membranes. Blotting membranes were blocked with TBS-T containing $5 \%(\mathrm{w} / \mathrm{v})$ bovine serum albumin and subsequently reacted with antibodies against ADA (Santa Cruz Biotechnology) or $\beta$-actin (Sigma, St Louis, MO, USA). After washing, membranes were reacted with a horseradish peroxidase-conjugated goat anti-rabbit IgG or goat anti-mouse IgG antibody. Immunoreactivity was detected with an ECL kit (GE Healthcare, Piscataway, NJ, USA) and visualized using a chemiluminescence detection system (GE Healthcare). Protein concentrations for each sample were determined with a BCA protein assay kit (Thermo Fisher Scientific).

\section{Assay of extra- and intra-cellular adenosine}

Nucleosides were extracted from cells or extracellular solutions by adding $2 \%$ trichloroacetic acid. After centrifugation at $5,000 \mathrm{~g}$ for $5 \mathrm{~min}$ at $4{ }^{\circ} \mathrm{C}$, the supernatants were loaded onto a reversed phase highperformance liquid chromatography (HPLC)(LC-10ATvp; Shimadzu Co., Kyoto, Japan). An adenosine peak was detected at an absorbance of $260 \mathrm{~nm}$ (SPD-10Avp UV-VIS detector, Shimadzu Co.), and adenosine was quantified.

Evaluation of tumor growth in mice inoculated with NCI-H2052 cells

All procedures have been approved by the Animal Care and Use Committee at Hyogo College of Medicine and were in compliance with the National Institutes of Health Guide for the Care and Use of Laboratory Animals. Nude KSN/Slc mice (male, $7 \mathrm{w}$ ), weighting the average of $26 \mathrm{~g}$, were obtained from Japan SLC, Inc. (Shizuoka, Japan). NCI-H2052 cells $\left(1 \times 10^{7}\right.$ cells) suspended in $200 \mu$ l of culture medium with $50 \%$ (v/v) matrigel (BD Biosciences, San Jose, CA, USA) was subcutaneously inoculated in the right flank of mice under pentobarbital general anesthesia. EHNA $(0.3 \mathrm{mg} / \mathrm{kg}$, corresponding to $1 \mu \mathrm{mol} / \mathrm{kg}$ in $100 \mu \mathrm{l}$ of PBS $)$ or $100 \mu \mathrm{l}$ of PBS was intraperitoneally injected to mice three times a week. The longer (L) and shorter length $(\mathrm{S})$ of inoculated tumors was measured using calipers and tumor volume (V) was calculated according to the following equation: $\mathrm{V}=\mathrm{L} \times \mathrm{S}^{2} \times 0.5$.

Statistical analysis

Statistical analysis was carried out using unpaired $t$-test and Dunnett’s test.

\section{Results}

EHNA induces apoptosis of cancer cells

For the MPM cell lines NCI-H28, NCI-H2052, NCI-H2452, and MSTO-211H cells, EHNA reduced cell viability in a concentration (0.01-1 mM)- and treatment time (24-48 h)dependent manner, reaching below $20 \%$ of basal levels at 48 -h treatment at $1 \mathrm{mM}$ (Fig. 1A-D). In the TUNEL staining, EHNA (1 mM) significantly increased the number of TUNEL- 


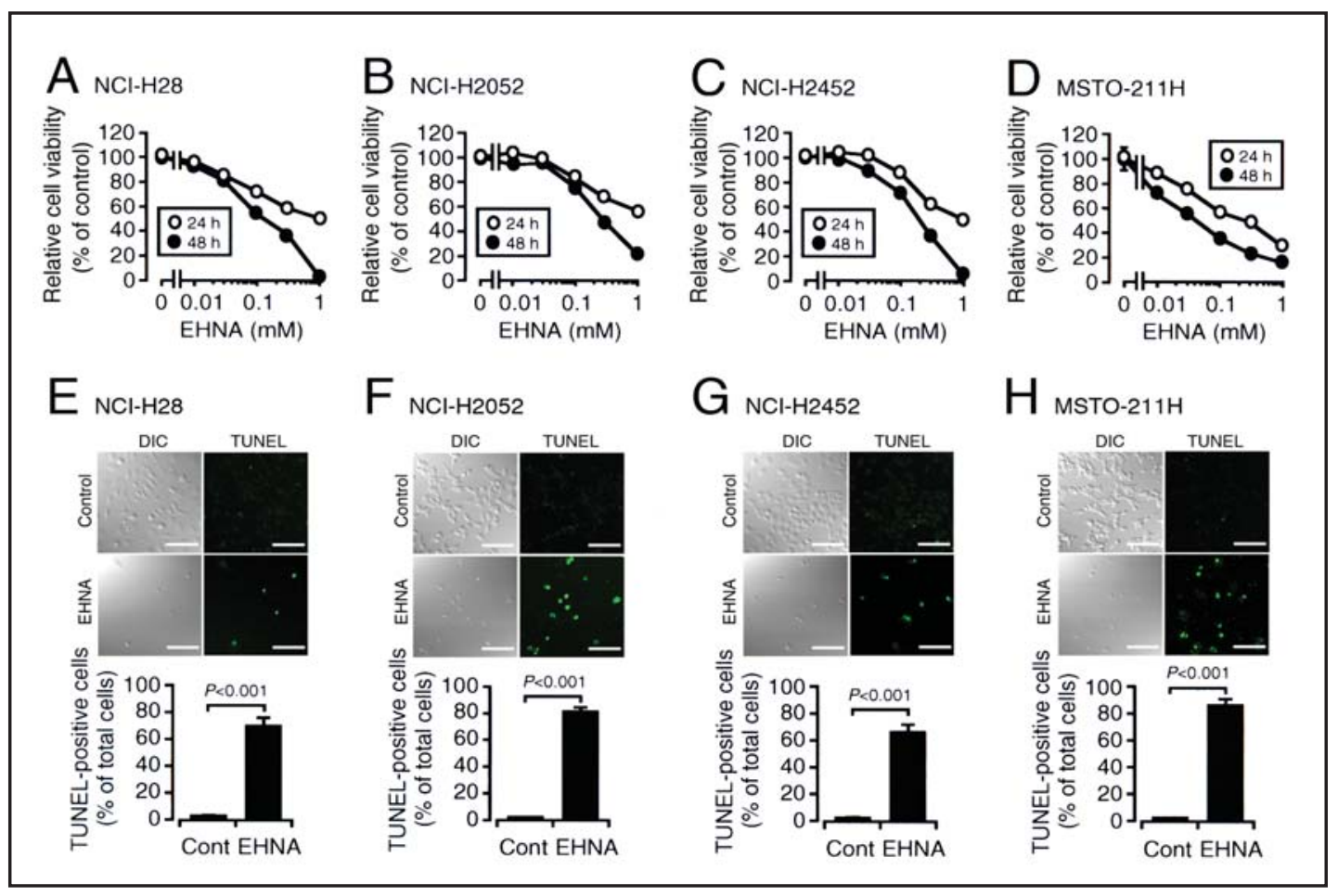

Fig. 1. EHNA-induced apoptosis of MPM cells. MTT assay was carried out in NCI-H28 (A), NCI-H2052 (B), NCI-H2452 (C), and MSTO-211H cells (D), untreated and treated with EHNA at concentrations as indicated for 24-48 h. In the graphs, each point represents the mean $( \pm$ SEM) percentage of control (MTT intensities for cells untreated with EHNA)( $\mathrm{n}=4$ independent experiments). TUNEL staining was carried out in NCI-H28 (E), NCI-H2052 (F), NCI-H2452 (G), and MSTO-211H cells (H), untreated (Cont) and treated with EHNA (1 $\mathrm{mM}$ ) for $24 \mathrm{~h}$. DIC, differential interference contrast. Bars, $100 \mu \mathrm{m}$. TUNEL-positive cells were counted in the area $(0.4 \mathrm{~mm} \times 0.4 \mathrm{~mm})$ selected at random. In the graphs, each column represents the mean $( \pm$ SEM) TUNEL-positive cell percentage of whole cells ( $\mathrm{n}=4$ independent experiments). $P$ values, unpaired $t$-test.

positive cells as compared with that for untreated control cells for all the investigated MPM cell lines (Fig. 1E-H), indicating that EHNA induces apoptosis of MPM cells.

Likewise, EHNA reduced cell viability for the human lung cancer cell lines A549, SBC-3, and Lu-65 cells and the human hepatic cancer cell lines HepG2 and HuH-7 cells in a concentration (0.01-1 $\mathrm{mM}$ )- and treatment time (24-48 h)-dependent manner (Fig. 2A-C,G,H) and definitely increased TUNEL-positive cells for these cell lines (Fig. 2D-F,I,J). Taken together, these results indicate that EHNA has the potential to induce apoptosis of a variety of cancer cells.

Surprisingly, another ADA inhibitor pentostatin had no/little effect on cell viability for all the investigated MPM cell lines (Fig. 3A-D).

\section{EHNA increases intracellular adenosine concentrations in MPM cells}

We next examined whether EHNA actually increases adenosine concentrations in MPM cells. Expectedly, EHNA (0.3 mM) increased intracellular adenosine concentrations in a treatment time (3-9 h)-dependent manner for all the investigated MPM cell lines, while extracellular adenosine concentrations were not increased or conversely decreased (Fig. 4AD).

Apoptosis of MPM cells is induced by knocking-down ADA

To ascertain whether EHNA-induced apoptosis of MPM cells is due to ADA inhibition, the $A D A$ siRNA was constructed and transfected into cells. Expression of ADA protein for 


\section{Cellular Physiology and Biochemistry}

Cell Physiol Biochem 2015;35:51-60

DOI: 10.1159/000369674

Published online: January 02, 2015

Nakajima et al: EHNA-Induced Cancer Cell Apoptosis
Fig. 2. EHNA-induced apoptosis of human lung and hepatic cancer cells. MTT assay was carried out in A549 (A), SBC-3 (B), Lu-65 (C), HepG2 (G), and HuH-7 cells (H), untreated and treated with EHNA at concentrations as indicated for 24-48 h. In the graphs, each point represents the mean $( \pm$ SEM) percentage of control (MTT intensities for cells untreated with EHNA)( $n=4$ independent experiments). TUNEL staining was carried out in A549 (D), SBC-3 (E), Lu-65 (F), HepG2 (I), and HuH-7 cells (J), untreated (Cont) and treated with EHNA (1 mM) for $24 \mathrm{~h}$. DIC, differential interference contrast. Bars, $100 \mu \mathrm{m}$. TUNEL-positive cells were counted in the area $(0.4 \mathrm{~mm} \times 0.4 \mathrm{~mm})$ selected at random. In the graphs, each column represents the mean ( \pm SEM) TUNEL-positive cell percentage of whole cells $(\mathrm{n}=4$ independent experiments). $P$ values, unpaired $t$-test.

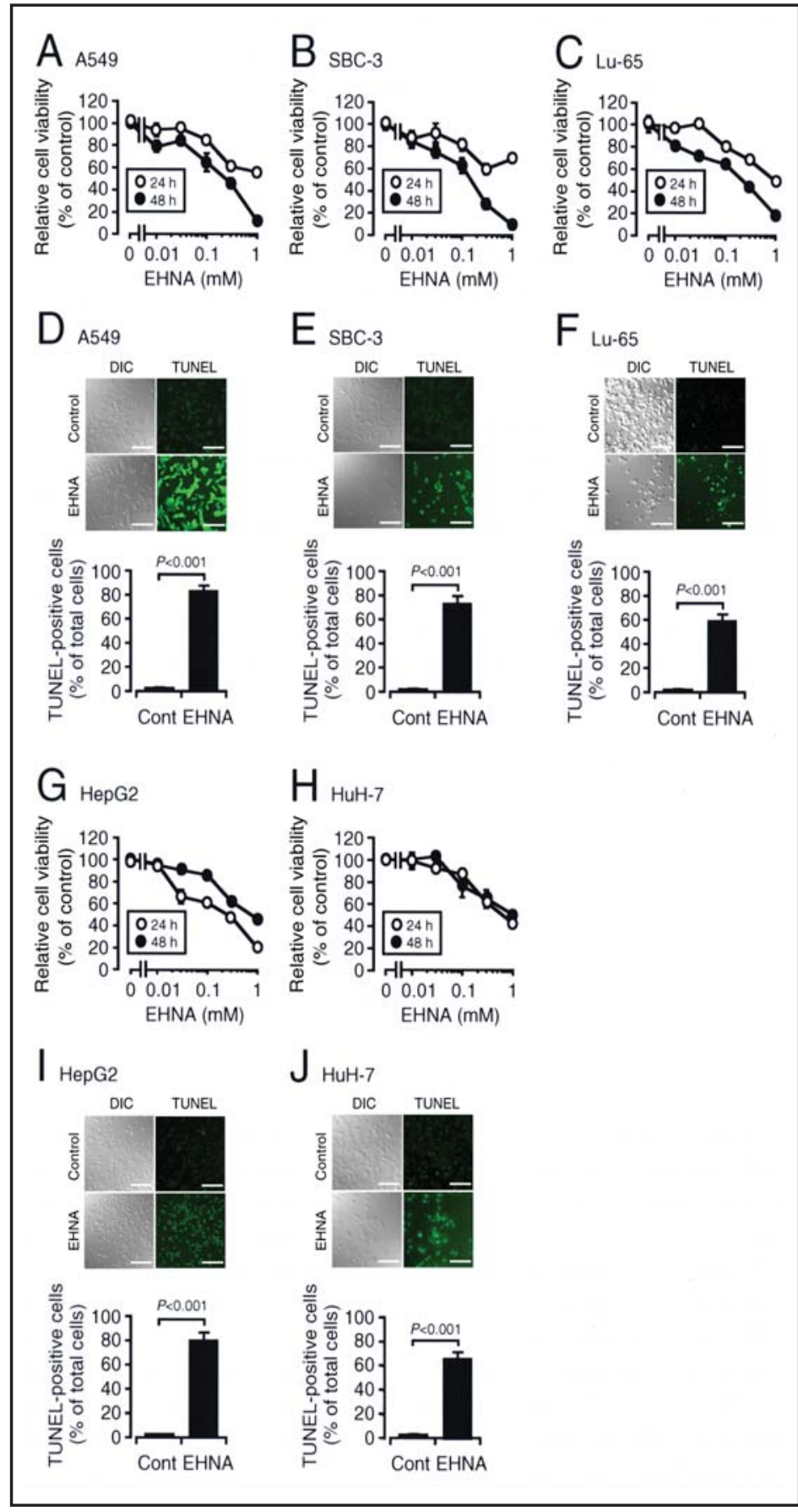

cells transfected with the ADA siRNA was clearly decreased (Fig. 5A-D), confirming ADA knock-down. Cell viability for NCI-H28, NCI-H2052, NCI-H2452, and MSTO-211H cells was significantly reduced by knocking-down ADA, and the effect was neutralized by the adenosine kinase inhibitor 4-amino-5-(3-bromophenyl)-7-(6-morpholino-pyridin-3-yl) pyrido[2,3-d] pyrimidine (ABT-702) (Fig. 6A-D). Moreover, a significant increase in TUNELpositive cells was found for all the investigated MPM cell lines by knocking-down ADA (Fig. 6E-H). Collectively, these results suggest that EHNA increases intracellular adenosine concentrations by inhibiting ADA and that in turn, adenosine kinase-catalyzed conversion to AMP triggers apoptosis of MPM cells. 
Fig. 3. Effect of pentostatin on MPM cell viability. MTT assay was carried out in NCI-H28 (A), NCI-H2052 (B), NCIH2452 (C), and MSTO-211H cells (D), untreated and treated with pentostatin at concentrations as indicated for 24-48 h. In the graphs, each point represents the mean $( \pm$ SEM) percentage of control (MTT intensities for cells untreated with pentostatin $)(n=4$ independent experiments).

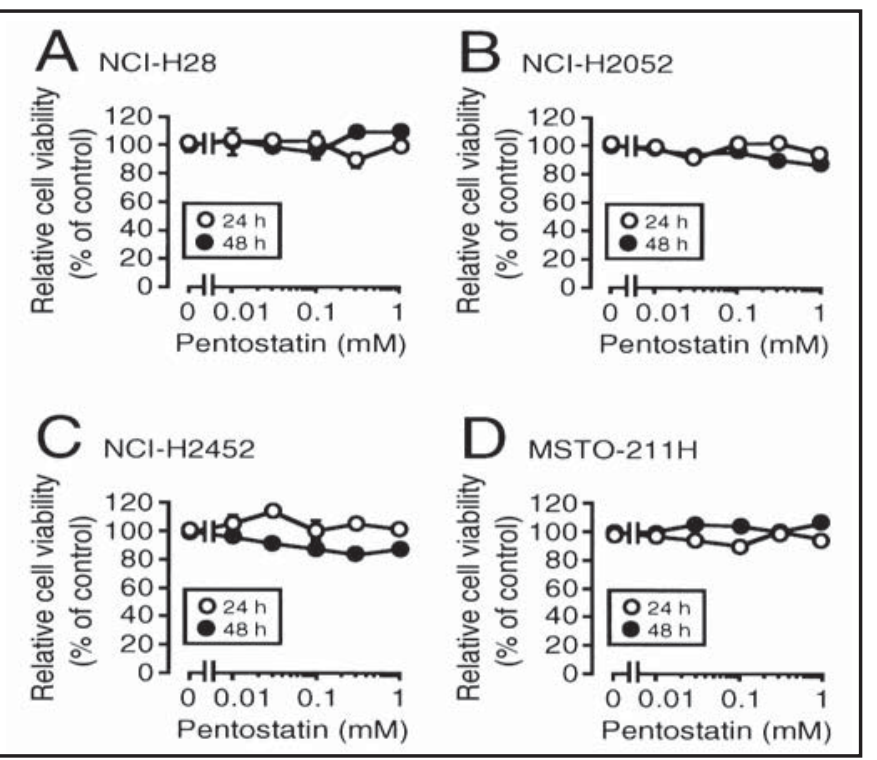

Fig. 4. Effects of EHNA on extra- and intra-cellular adenosine concentrations. NCI-H28 NCI-H2052 (B), NCI-H2452 (C), and MSTO-211H cells (D) were treated with EHNA $(0.3 \mathrm{mM})$ for 3-9 $\mathrm{h}$, and then extra- and intracellular adenosine were quantified by HPLC. In the graphs, each point represents the mean $( \pm$ SEM) adenosine concentration ( $\mu \mathrm{M}$ for extracellular adenosine, $\mathrm{nmol} / \mathrm{mg}$ protein for intracellular adenosine $)(n=4$ independent experiments).

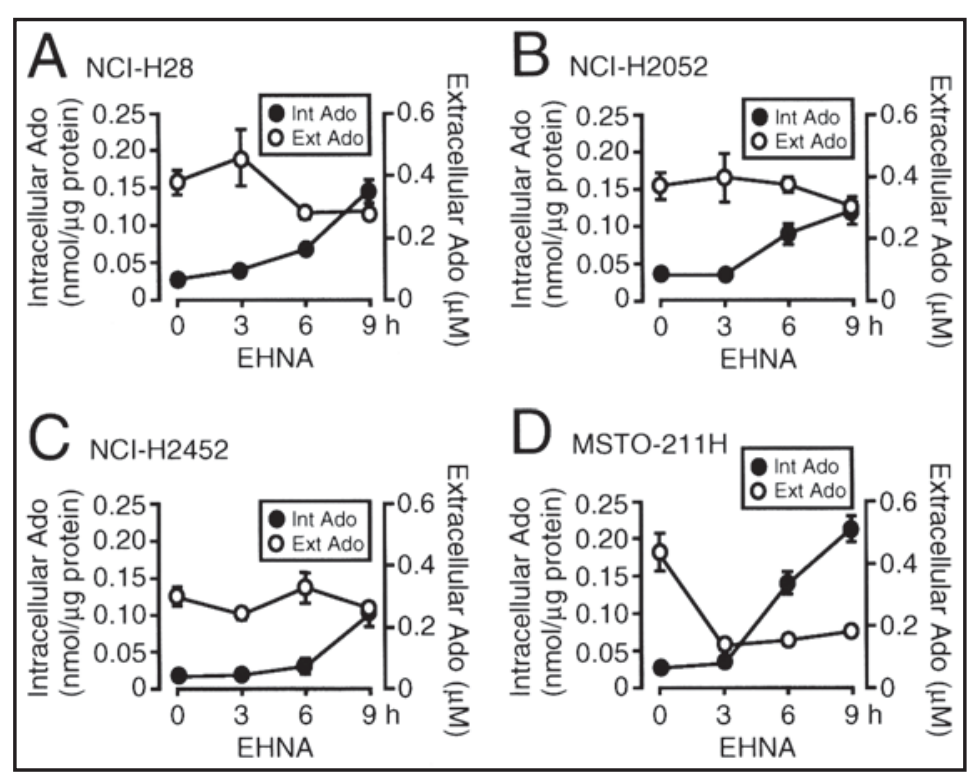

Fig. 5. ADA knockdown. NCI-H28 (A), NCI-H2052 (B), NCI$\mathrm{H} 2452$ (C), and MSTO- $211 \mathrm{H}$ cells (D) were transfected with the $N C$ SiRNA or the $A D A$ siRNA followed by Western blotting $48 \mathrm{~h}$ after transfection. Signal intensities for ADA
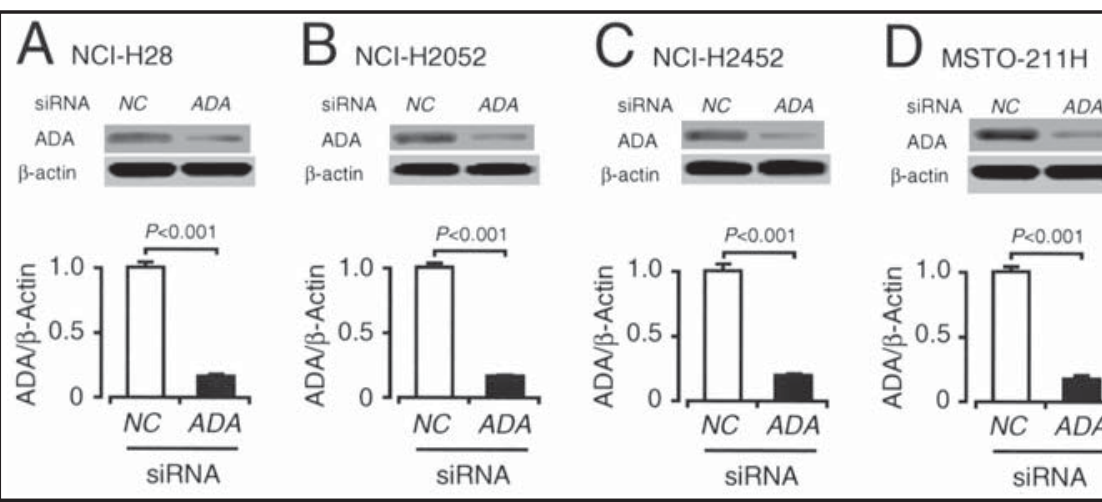

protein were normalized by those for $\beta$-actin. In the graphs, each column represents the mean ( \pm SEM) ADA protein intensity ( $\mathrm{n}=4$ independent experiments). $P$ values, unpaired $t$-test. 

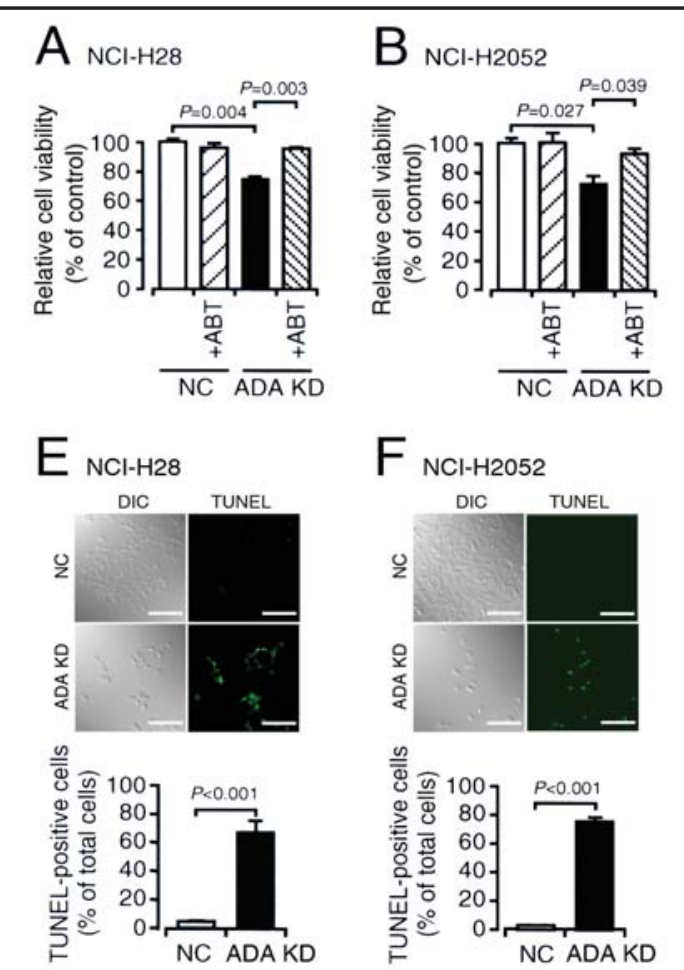
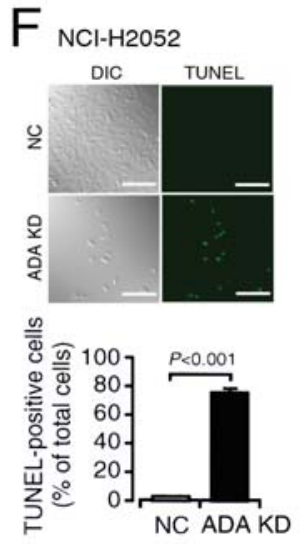

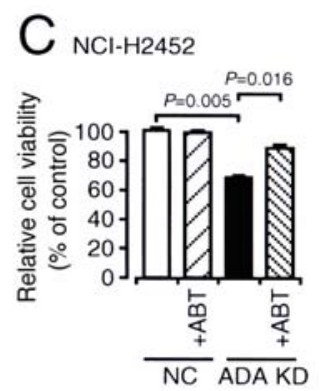

$\mathrm{G}$
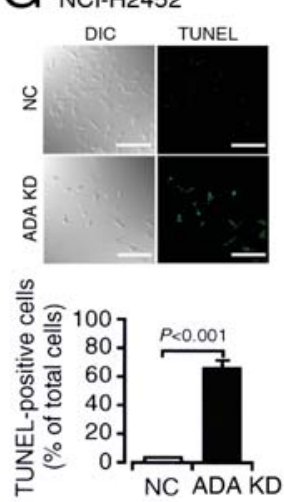

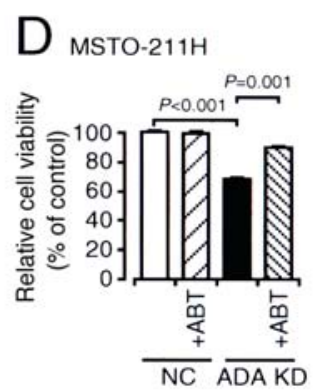

$\mathrm{H}_{\text {мSTO-211H }}$
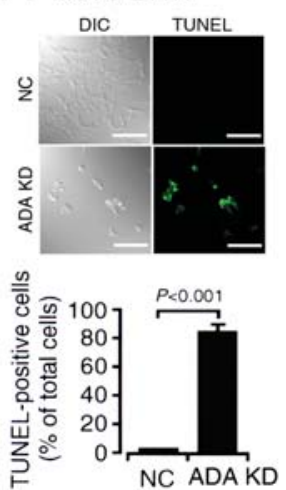

Fig. 6. MPM cell apoptosis is induced by knocking-down ADA. MTT assay was carried out in NCI-H28 (A), NCI-H2052 (B), NCI-H2452 (C), and MSTO-211H cells (D) transfected with the NC siRNA (NC) or the ADA siRNA (ADA KD) $48 \mathrm{~h}$ after transfection in the presence and absence of ABT-702 (ABT)(10 nM). In the graphs, each column represents the mean $( \pm$ SEM) percentage of control (MTT intensities for cells transfected with the $N C$ siRNA at $48 \mathrm{~h}$ after transfection)(n=4 independent experiments). $P$ values, Dunnett's test. TUNEL staining was carried out in NCI-H28 (E), NCI-H2052 (F), NCI-H2452 (G), and MSTO-211H cells (H) transfected with the $N C$ siRNA (NC) or the ADA siRNA (ADA KD) $48 \mathrm{~h}$ after transfection. DIC, differential interference contrast. Bars, $100 \mu \mathrm{m}$. TUNEL-positive cells were counted in the area ( $0.4 \mathrm{~mm} \times 0.4 \mathrm{~mm}) \mathrm{se}$ lected at random. In the graphs, each column represents the mean ( \pm SEM) TUNEL-positive cell percentage of whole cells ( $\mathrm{n}=4$ independent experiments). $P$ values, unpaired $t$-test.

Fig. 7. EHNA-induced suppression of NCI-H2052 MPM cell proliferation. NCI-H2052 cells were subcutaneously inoculated in the flank of mice, and PBS or EHNA $(0.3 \mathrm{mg} / \mathrm{kg})$ was intraperitoneally injected three times a week. Time-course change of tumor volume (the mean $\pm S E M)(n=6$ independent mice). ${ }^{*} P<0.05 ;{ }^{* *} P<0.01 ;{ }^{* * *} P<0.001$ as compared with that for PBS-injected control mice, unpaired $t$-test.

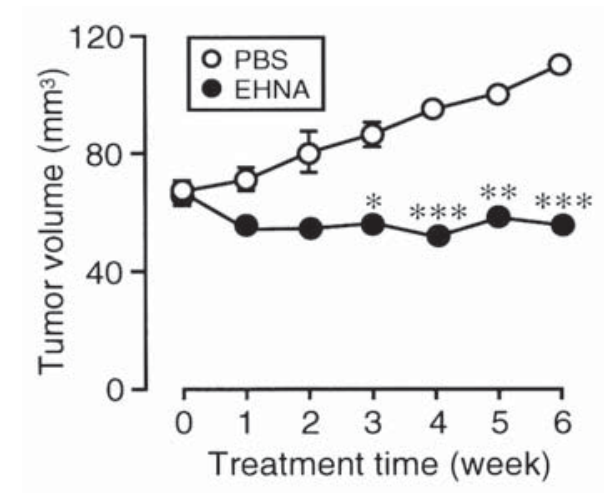

EHNA suppresses NCI-H2052 tumor growth

We finally examined the effect of EHNA on tumor growth in mice inoculated with $\mathrm{NCI}-\mathrm{H} 2052$ cells. Intraperitoneal injection with EHNA at a dose of $0.3 \mathrm{mg} / \mathrm{kg}$ drastically reduced NCI-H2052 cell growth as compared with that for PBS-injected control mice (Fig. 7). This indicates that EHNA exhibits a potent anticancer activity against MPM. 


\section{Cellular Physiology and Biochemistry}

Cell Physiol Biochem 2015;35:51-60

DOI: 10.1159/000369674

on Ine: January 02, 2015

\section{Discussion}

A growing body of evidence has shown that high concentrations of extracellular adenosine is capable of inducing apoptosis in a variety of cancer cells mainly through intrinsic and/or extrinsic pathways [1-20]. ADA, an enzyme involved in purine metabolism, catalyzes the hydrolytic deamination of adenosine and 2'-deoxyadenosine to their corresponding hypoxanthine derivatives, inosine and 2'-deoxy-inosine. ADA inhibition, therefore, results in the accumulation of adenosine, 2'-deoxyadenosine, and 2'-deoxyATP in cells [21, 22]. Indeed, the ADA inhibitor EHNA increased intracellular adenosine concentrations in MPM cells. EHNA induced apoptosis in all the investigated MPM cell lines, human lung cancer cell lines, and human hepatic cancer cell lines. This suggests that an increase in intracellular adenosine concentrations due to ADA inhibition is essential for EHNA-induced apoptosis of MPM cells. In support of this idea, apoptosis of MPM cells was induced by knocking-down ADA. Notably, MPM cell death due to ADA knock-down was prevented by the adenosine kinase inhibitor ABT-702. This implies that AMP, produced by adenosine kinase-catalyzed phosphorylation of adenosine, following an increase in intracellular adenosine concentrations due to ADA inhibition is a key factor for EHNA-induced apoptosis of MPM cells. EHNA clearly suppressed tumor growth in mice inoculated with NCI-H2052 cells. Overall, these results indicate that EHNA could be a beneficial drug for treatment of MPM.

The most paradoxical result in the present study is that another ADA inhibitor pentostatin, whereas it increases intracellular adenosine concentrations, had no/little effect on cell viability for all the investigated MPM cell lines. This raises the possibility that EHNAinduced apoptosis of MPM cells may not be induced simply by raising intracellular adenosine levels due to ADA inhibition and that the unknown additional mechanism may participate in the EHNA action. Pentostatin in combination of 2'-deoxyadenosine is show to activate caspase-3 and induce apoptosis of human monocytoid leukemia cells [23]. Pentostatin, alternatively, has a striking cytotoxic effect on different types of T-cell lymphomas, including T-prolymphocytic leukemia, large granular lymphocyte leukemia, and hepatosplenic $\mathrm{gd}^{+}$ T-cell lymphoma [24]. EHNA, on the other hands, acts as an inhibitor of cyclic nucleotide phosphodiesterase 2 (PDE2) as well as ADA [25]. Interestingly, PDE inhibitors could still induce cell death in a variety of cancer cells [26-28]. EHNA, accordingly, might exhibit an anticancer effect against MPM by inhibiting both ADA and PDE2. To answer this question, we are currently probing the target molecules responsible for EHNA-induced apoptosis of MPM cells.

Accumulating evidence has pointed that higher concentrations of adenosine induce apoptosis of a wide variety of cancer cells via intrinsic and extrinsic pathways [2-10]. This raises the possibility that adenosine is available for effective chemotherapy of cancers. Adenosine is an endogenous substance, and therefore, in use for chemotherapy less side effects are expected. From these points of view, EHNA, which induces MPM cell apoptosis by increasing endogenous adenosine concentrations, could be developed as a promising drug for MPM therapy. We are currently preparing for clinical challenge of ENHA.

In conclusion, the results of the present study clearly demonstrate that EHNA induces apoptosis of MPM cells and suppresses tumor growth in mice inoculated with NCI-H2052 cells. This may provide a new strategy for treatment of MPM.

\section{Acknowledgements}

This study was supported by research grants from 'the Takeda Science Foundation' and 'MEXT-Supported Program for the Strategic Research Foundation at Private Universities, 2012-2016'. 


\section{Cellular Physiology and Biochemistry}

Cell Physiol Biochem 2015;35:51-60

\begin{tabular}{l|l}
\hline DOI: $10.1159 / 000369674$ & (C) 2015 S. Karger AG, Basel
\end{tabular}

Nakajima et al.: EHNA-Induced Cancer Cell Apoptosis

\section{References}

1 Raja S, Murthy SC, Mason DP: Malignant pleural mesothelioma. Curr Oncol Rep 2011;13:259-264.

-2 Saitoh M, Nagai K, Nakagawa K, Yamamura T, Yamamoto S, Nishizaki T: Adenosine induces apoptosis in the human gastric cancer cells via an intrinsic pathway relevant to activation of AMP-activated protein kinase. Biochem Pharmacol 2004;67:2005-2011.

-3 Yang D, Yaguchi T, Nakano T, Nishizaki T: Adenosine activates AMPK to phosphorylate Bcl-XL responsible for mitochondrial damage and DIABLO release in HuH-7 cells. Cell Physiol Biochem 2011;27:71-78.

-4 Wu LF, Li GP, Feng JL, Pu ZJ: Molecular mechanisms of adenosine-induced apoptosis in human HepG2 cells. Acta Pharmacol Sin 2006;27:477-484.

-5 Yang D, Yaguchi T, Yamamoto H, Nishizaki T: Intracellularly transported adenosine induces apoptosis in HuH-7 human hepatoma cells by downregulating c-FLIP expression causing caspase-3/-8 activation. Biochem Pharmacol 2007;73:1665-1675.

6 Yang D, Yaguchi T, Nakano T, Nishizaki T: Adenosine-induced caspase-3 activation by tuning Bcl- $\mathrm{X}_{\mathrm{L}} /$ DIABLO/IAP expression in HuH-7 human hepatoma cells. Cell Biol Toxicol 2010;26:319-330.

7 Tsuchiya A, Kanno T, Saito M, Miyoshi Y, Gotoh A, Nakano T, Nishizaki T: Intracellularly transported adenosine induces apoptosis in MCF-7 human breast cancer cells by accumulating AMID in the nucleus. Cancer Lett 2012;321:65-72.

8 Nogi Y, Kanno T, Nakano T, Fujita Y, Tabata C, Fukuoka K, Gotoh A, Nishizaki T: AMP converted from intracellularly transported adenosine upregulates p53 expression to induce malignant pleural mesothelioma cell apoptosis. Cell Physiol Biochem 2012;30:61-74.

-9 Saito M, Yaguchi T, Yasuda Y, Nakano T, Nishizaki T: Adenosine suppresses CW2 human colonic cancer growth by inducing apoptosis via $A_{1}$ adenosine receptors. Cancer Lett 2010;290:211-215.

- 10 Sai K, Yang D, Yamamoto H, Fujikawa H, Yamamoto S, Nagata T, Saito M, Yamamura T, Nishizaki T: A adenosine receptor signal and AMPK involving caspase-9/-3 activation are responsible for adenosineinduced RCR-1 astrocytoma cell death. Neurotoxicol 2006;27:458-467.

-11 Yasuda Y, Saito M, Yamamura T, Yaguchi T, Nishizaki T: Extracellular adenosine induces apoptosis in Caco-2 human colonic cancer cells by activating caspase- $9 /-3$ via $A_{2 a}$ adenosine receptors. J Gastroenterol 2009; 44:56-65.

-12 Tamura K, Kanno T, Fujita Y, Gotoh A, Nakano T, Nishizaki T: A $\mathrm{z}_{\mathrm{a}}$ adenosine receptor mediates HepG2 cell apoptosis by downregulating Bcl- $\mathrm{X}_{\mathrm{L}}$ expression and upregulating Bid expression. J Cell Biochem 2012;113:1766-1775.

-13 Kamiya H, Kanno T, Fujita Y, Gotoh A, Nakano T, Nishizaki T: Apoptosis-related gene transcription in human A549 lung cancer cells via $A_{3}$ adenosine receptor. Cell Physiol Biochem 2012;29:687-696.

14 Otsuki T, Kanno T, Fujita Y, Tabata C, Fukuoka K, Nakano T, Gotoh A, Nishizaki T: A adenosine receptormediated p53-dependent apoptosis in Lu-65 human lung cancer cells. Cell Physiol Biochem 2012;30:210220.

-15 Kanno T, Nakano T, Fujita Y, Gotoh A, Nishizaki T: Adenosine induces apoptosis in SBC-3 human lung cancer cells through $\mathrm{A}_{3}$ adenosine receptor-dependent AMID upregulation. Cell Physiol Biochem 2012;30:666677.

16 Bar-Yehuda S, Stemmer SM, Madi L, Castel D, Ochaion A, Cohen S, Barer F, Zabutti A, Perez-Liz G, Del Valle L, Fishman P: The $\mathrm{A}_{3}$ adenosine receptor agonist CF102 induces apoptosis of hepatocellular carcinoma via de-regulation of the Wnt and NF-kB signal transduction pathways. Int J Oncol 2008;33:287-295.

17 Morello S, Sorrentino R, Porta A, Forte G, Popolo A, Petrella A, Pinto A: Cl-IB-MECA enhances TRAILinduced apoptosis via the modulation of NF-kB signalling pathway in thyroid cancer cells. J Cell Physiol 2009;221:378-386.

-18 Panjehpour M, Karami-Tehrani F: Adenosine modulates cell growth in the human breast cancer cells via adenosine receptors. Oncol Res 2007;16:575-585.

19 Nagaya H, Gotoh A, Kanno T, Nishizaki T: A adenosine receptor mediates apoptosis in in vitro RCC4-VHL human renal cancer cells by up-regulating AMID expression. J Urol 2013;189:321-328.

20 Kanno T, Gotoh A, Fujita Y, Nakano T, Nishizaki T: A adenosine receptor mediates apoptosis in 5637 human bladder cancer cells by $\mathrm{G}_{\mathrm{q}}$ protein/PKC-dependent AIF upregulation. Cell Physiol Biochem 2012;30:11591168. 


\section{Cellular Physiology Cell Physiol Biochem 2015;35:51-60 \\ \begin{tabular}{ll|l} 
and Biochemistry & $\begin{array}{l}\text { DOI: 10.1159/000369674 } \\
\text { Publisned onme: January 02, } 2015\end{array}$ & $\begin{array}{l}\text { ○ 2015 S. Karger AG, Basel } \\
\text { www.karger.com/cpb }\end{array}$ \\
\cline { 2 - 3 }
\end{tabular}}

Nakajima et al.: EHNA-Induced Cancer Cell Apoptosis

21 Carson DA, Kaye J, Seegmiller JE: Differential sensitivity of human leukemic T cell lines and B cell lines to growth inhibition by deoxyadenosine. J Immunol 1978;121:1726-1733.

-22 Cohen A, Hirschhorn R, Horowitz SD, Rubinstein A, Polmar SH, Hong R, Martin DWJr: Deoxyadenosine triphosphate as a potentially toxic metabolite in adenosine deaminase deficiency. Proc Natl Acad Sci USA 1978;75:472-476.

23 Niitsu N, Yamaguchi Y, Umeda M, Honma Y: Human monocytoid leukemia cells are highly sensitive to apoptosis induced by 2'-deoxycoformycin and 2'-deoxyadenosine: association with dATP-dependent activation of caspase-3. Blood 1998;92:3368-3375.

24 Kurzrock R: Pentostatin (Nipent) in T-cell lymphomas. Semin Oncol 2000;27:64-66.

25 Haynes J Jr, Killilea DW, Peterson PD, Thompson WJ: Erythro-9-(2-hydroxy-3-nonyl)adenine inhibits cyclic-3',5'-guanosine monophosphate-stimulated phosphodiesterase to reverse hypoxic pulmonary vasoconstriction in the perfused rat lung. J Pharmacol Exp Ther 1996;276:752-757.

-26 Mentz F, Merle-BCral H, Ouaaz F: Theophylline, a new inducer of apoptosis in B-CLL: role of cyclic nucleotides. Br J Haematol 1995;90:957-959.

27 Janik P, Assaf A, Bertram JS: Inhibition of growth of primary and metastatic lewis lung carcinoma cells by the phosphodiesterase inhibitor isobutylmethylxanthine. Cancer Res 1980;40:1950-1954.

28 Thompson WJ, Piazza GA, Li H, Liu L, Fetter J, Zhu B, Sperl G, Ahnen D, Pamukcu R: Exisulind induction of apoptosis involves guanosine 3',5'-cyclic monophosphate phosphodiesterase inhibition, protein kinase G activation and attenuated $\beta$-catenin. Cancer Res 2000;60:3338-3342. 